\title{
The Dynamics of Social Media Metrics and Intensity of Customer Relationship-An Empirical Investigation of the IT Industry
}

\author{
Lan-Lan DONG ${ }^{1,2, a,{ }^{*}}$, Ying-Hong WAN ${ }^{1,2, b}$, Xiao-Juan WANG ${ }^{1,2,3, c}$ \\ ${ }^{1}$ School of Management, Xi'an Jiaotong University, Xi'an, Shaanxi, China 710049 \\ ${ }^{2}$ Experiment Center for Management Teaching \&Learning, Xi'an Jiaotong University \\ ${ }^{3}$ School of Finance and Economics, Tibet Institute for Nationalities, Xianyang, Shaanxi, 712082 \\ axiaopinge2013@stu.xjtu.edu.cn, bwanyh@maiil.xitu.edu.cn, cwxjsfping_ok@126.com \\ ${ }^{\star}$ Corresponding author
}

Keywords: Social media, Customer participation, Firm's effort, Customer relationship.

\begin{abstract}
Based on the theory of customer lifecycle and prior literature, we classify the customers into segments, thus to examine the effects of social media on the relationship between the firm and its customer segments. The results derived from vector autoregressive models suggest that, generally, social media metrics significantly and positively influence the customer relationship, but the effect will dissipate in the long run. Interestingly, social media metrics affect the two customer segments differently; the impact on the preliminary customers is stronger than the stables ones. We also find, among the three metrics of social media, brand community best relates to the connections between customers and the firm.
\end{abstract}

\section{Introduction}

Social media has revolutionized the ways organizations relate to the marketplace and society, creating a new world of possibilities and challenges for all aspects of the firm. Customer relationship management is a core organizational process that focuses on establishing, maintaining, and enhancing associations with customers, which is vital to the success of organizational performance. Internet and related technologies, especially social media, have changed the way individuals interact with each other and are redefining the way firms connect with their customers. Remarkably, social media have provided various ways for the firm to communicate with their customers, such as brand communities, web blogs, et.al, to establish and strength the customer-firm relationship. In this sense, social media stimulates the intensity of customer-firm relationship when others (e.g. support services) are not available. Because social media can equip executives with the most updated information about the dynamics of how users interact with the firm, it may could provide some indication of how the relationship between potential, stable customers and the firm gradually develop and grow.

However, to justify the significant resources and investments in social media for well-maintained customer relationship, executives need to empirically quantify social media's impressive value. Our study investigates the three forms of social media--brand community, web blogs, and microblogs--after accounting for other fundamental explanations (such as product quality, ads) [1,2]. Social media offers companies multifarious ways to reach consumers, communicate with them, browsing or purchase-related behaviors, which are valuable for customer relationship management. In particular, this study seeks answers to the following questions:

- Dose social media, particularly brand communities, web blogs and microblogs, really have effects on the customer-firm relationship ? And what are the dynamics of the effects in terms of wear-in, wear-out, and duration?

-Does social media metric influence different customer segments (e.g. The preliminary and stable customers) differently? 
-Among the various metrics of social media, what metric best relates to the customer-firm relationship?

\section{Theoretical Background and Hypotheses}

The focus of this study is on examining how social media efforts by the firm and customer participation help transform the customer-firm relationships. Based on customer lifecycle, we measure the relationship from two aspects, one is a key characteristic representing customers' preliminary relationship with the firm-keywords search intensity, another is representing stable connections - numbers of loyalty customers. In examining the impact of social media metrics participation on the intensity of customer-firm relationship, we focus on two sets of factors that can influence the connections: (a) Customers’ Participation in Social Media Metrics and (b) Effect of Social Media Activity by the Firm.

\section{Customers' Participation in Social Media Metrics}

Customers can strengthen their relationship with the firm by participating in social media. According to Rishika et al. [3], firm hosted social media opens a new channel of communication through which customers can connect and communicate directly with the firm and other customers that will affect the intensity of customer-firm relationship. In this study, we explore three metrics of the firm hosted social media, namely, brand communities, web blogs and microblogs. A brand community from a customer-experiential perspective is a fabric of customer relationships which includes those between the customer and the brand, between the customer and the firm, between the customer and the product in use, and among fellow customers. Researches suggest that web blogs, as one of the most typical social media, have a significantly simulative effect on customer engagement [4,5]. Right after the blooming of brand communities and web blogs, microblogs appeared and grew quickly. Several literature has explore the value of microblogs from various aspects [6,7], however, few research considered the relationship between microblogs with business intelligence, especially with the CRM. In this study, we examine whether customer participation in microblogs has a impact on the customer-firm relationship. Based on the above discussion, we hypothesize the following:

Hypothesis 1 (H1). Customer participation in social media metrics will have a positive impact on the customer-firm relationship.

\section{Effect of Social Media Activity by the Firm}

We believe that the level of activity in the social media site in terms of the number of messages posted by the firm and other customers will influence the customer-firm relationship. Prior research suggests that commitment and trust in a relationship are positively associated with a party's intentions to continue the relationship with the other party [8]. Further, in the context of a social media site, by scrutinizing information and messages, customers can feel more confident about their own behaviors, thus impacting their intensity of relationship with the firm. In this sense, an active social media page with regular new messages/postings can help the firm strengthen the customer-firm relationship. In this study, we only measure social media activity by the firm for two reasons. First, because one of the main purposes of the firm hosted social media sites is to create a platform for communicating with its customers and building relationships with them, a firm must maintain a high level of activity on the social media site [5] and these sites are mainly managed by specific officers who work for the firm. Second, customers engage in the social media more usually for seeking information they are interested in than sharing or posting their own experience, thus most of the social media content is provided by the firm. Hence, we hypothesize that a higher level of activity (e.g., web blogs, microblogs, answers response to customers) on the social media site posted by the firm will influence the customer-firm relationship. 
Hypothesis 2 (H2). Social media activity by the firm will have a positive impact on the customer-firm relationship.

\section{Social Media's Impact on Customer Segments Relationship}

Social media has become a preferred platform for establishing, maintaining and enhancing meaningful relationships between firms and their customers. However, the impact of social media participation for different segments of customers varies [9], thus demarketing gradually emerged. Based on the theory of customer lifecycle, the most obvious difference is between the firm's preliminary customers and the stable ones. While the former group of customers have just contacted the firm for only several times and not thoroughly familiar with its products or services, such preliminary customers participate in the firm's social media mainly for easy access to information on firms' offerings and other related messages. In this sense, with growing participating in social media sites hosted by the firm, preliminary customers will become more favorably disposed toward the firm and strengthen the connection with the firm. However, the stable customers have already profoundly got information about the firm, maintained a strong tie with the firm, and greatly trust products/services provided by it. In such situation, they will don't have to participate in the firm's social media to seek information. Compared with preliminary customers, these segments of customers would more like to share experience for other customers, or voice innovative ideas for new product design. Intuitively and obviously, social media metrics hosted by the firm have a stronger impact on the preliminary customers than the stable ones.

Hypothesis 3 (H3). The impact of social media participation metrics both from the firm and customers' effort on the preliminary customers is stronger than the stable customers.

We next turn to the data that we use to test the above hypotheses.

\section{Data and Measures}

In this study, we selected IT industry as our research context for the following reasons. First, according to Moore's Law, IT products have experienced rapid technological advancements with reduced life cycles. Second, customers of IT products are more likely to participate in and be affected by social media. Within the computer hardware and software industries, we selected Microsoft, for this firm has created all social media metrics that we mentioned above.

\section{Data and Measures for Customer-firm Relationship}

The dependent variable for our analysis is the intensity of customer-firm relationship. Based on the theory of customer lifecycle and prior literature on the impact of social media on customers-firm relationship $[10,11]$, this study classify customers into two types, preliminary customers who are not very familiar with the firm and stable customers who are loyalty to the firm's products/services. In this study, we analyze if customers' social media participation affects the customer-firm relationship, and further, we will examine whether social media metrics hosted by the firm (a.g. brand communities, web blogs, microblogs) influence the relationship differently between those two types of customer segments. As has been analyzed above, we believe that this two types of customer segments won't behave the same in social media metrics. For our purposes, following precedence and the above analysis(the beginning of section 2) we use search intensity (denoted by Searchin) and number of loyalty customers (denoted by NO.loyalty) measuring the intensity of preliminary and stable customer-firm relationship respectively.

We obtained the data of Searchin from the Google Insights provided by the most popular search engine of Google. In this study, we calculated the mean of "firm key words" search frequencies at google.com as the Searchin. The key words for the selected firm, Microsoft, are based on the top and typical 8 query key words from search engines provided by Alexa. The another dependent variable is NO.loyalty, it is not easy to collect the precise number of loyalty customers of the firm, we substitutively choose to measure the total number of fans in the firm's hosted Sina weibo for the 
variable NO.loyalty. No doubts that if the group of customers are not loyal to Microsoft, they won't willingly to actively pay close attention to Microsoft's dynamics all the time.

\section{Data and Measures for Social Media Metrics}

For social media metrics, we collected data from the firm's hosted brand communities, web blogs and microblogs respectively at the daily level.

Data and Measures for Brand Communities. Before collecting data, we first analyze the characteristics of Microsoft brand communities. The main community for Microsoft integrates about 11 subcommunities for different types of products/service. Customers could ask questions if they encounter practical problems and will be answered by the specific officers. Thus, in our study, customer participation in brand community has two dimensions. One is the total number of questions in the whole 11 brand communities (denoted by CommunityQ ). Following prior literature, the other dimension is visit frequency (denoted by CommunityFreq). We collected CommunityFreq from Alexa.com, a popular source widely adopted by academic and practical research. Accordingly, we analyze if this two dimensions of customer participation in brand communities affect the intensity of customer-firm relationship. In the main brand community hosted by Microsoft, from the perspective of the firm's efforts, Microsoft helps customers to solve problem by answering their questions every day except the legal holidays. In this sense, we choose to summarize the total answers provided by the firm as measuring the firm's efforts in the brand community (denoted by CommunityA).

Data and Measures for Web Blogs. We collected data for Web blogs about the targeted firm and its products via the several authority sites of web blogs, e.g. "The windows blog" and "MSDN blogs" for two reasons. As we mainly research the effects from customer participation and the firm's efforts, which are not related to whether there are blogs about the targeted firm on other sites. Considering customer participation, we take visit frequency measuring customer participation in web blogs (denoted by Blogfreq) at the daily level, as well as in brand communities. We donnot calculate the number of comments by customers for the reason that the data at the daily level is too small, even zero, and there is no significant meaning to include this kind of variable. From the firm's effort perspective, we choose to count the total number of blogs posted on the two sites (denoted by NO.blogs).

Data and Measures for Microblogs. We collected microblogs data metrics from Sina weibo, the most popular site of microblogs in China adopted by academic and practical research. The targeted firm, Microsoft, has registered more than ten authority accounts on that platform. In this study, we exclude those accounts that have weak ties and donnot regularly renew informations, finally, ten accounts of microblogs hosted by the firm were selected. However, in terms of customer participation in the sites of microblogs, there is no manners to calculate the customers' visit frequency, we take the number of retwitts substitutivity as the proxy (denoted by Retwitts). Just like in the web blog data metrics, we summarize the total number of microblogs posted by the firm as Microsoft's efforts in this social media (denoted by No.Miblogs).

We also include in our model two control variables such as product quality and ads posted on the third party (quality). Product quality is measured by the customer rating from a Chinese third party (JD) and ads is measured through a popular site (CNET) at the daily level.

\section{VARX Model Specification}

We employ a time-series technique using the vector autoregression accounting for exogenous variables(VARX) for our empirical investigation. First, VARX is appropriate for this study as opposed to event studies, because both customers and the firm participate in social media metrics continuously over time and is not a discrete event. Second, it allows us to treat all of the key variables as jointly endogenous (assuming exogeneity of some of the variables), and to explicate dynamic effects, such as the impact of a shock in one variable on other variables over time. Third, it 
captures the dynamics of carryover effects over time through the generalized impulse response functions, which is robust to the assumptions of causal ordering of the variables and also assesses the relative contribution of the different metrics of social media participation through forecast error variance decomposition.

We specify the relationship among the metrics of social media and customer-firm relationship through the following VAR model (with exogenous variables):

$$
\gamma_{t}=\sum_{n=1}^{p} \Gamma_{n} \gamma_{t-n}+\Phi X_{t}+e_{t}
$$

where, $t \in\left\{T_{0}, T_{1}, T_{2}, \ldots, T\right\}$ is the time period index, $\gamma$ is the vector of the endogenous variables in the system, $\Gamma_{n}$ are the coefficients matrices of the lags of endogenous variables, $X$ is the vector of control variables(the exogenous variables) and $\Phi$ is its coefficients, and $e$ is the error term. The optimal lag order ("n") for the VAR model is chosen by the Akaike information criterion (AIC) and the Schwarz Bayesian information criterion (BIC). Specifically, we allow for various lag lengths in the model and select the lag order with the minimized AIC and BIC. The optimal lag order was three according to these criteria for our models. We specify the variables in levels or first differences, depending on the order of integration of the variables, which is determined through the unit root and cointegration tests. For example, the metrics of social media except Retwitt and No.loyalty enter the model in first differences because they are stationary in their first difference but not in the levels, and they also do not exhibit cointegration. Taking these factors into account, We estimate a 9 equation VARX model.

\section{Results}

\section{Tests for Stationarity and Granger Causality}

The process of estimating VARX models begins with the unit-root tests to check whether variables are stationary. We use the ADF test to determine its stationarity with the KPSS test to ensure that our results are robust to assumptions of null hypothesis of unit root. The ADF tests of almost all metrics across firms are more than the critical value -2.89 and cannot reject the null hypothesis of a unit root with a 95\% confidence level, except for searchin series and retwitt series. We then use the first differences for those unstable metrics. The ADF test results for the corrected data series range from -36.65 to -2.92, suggesting that the variable series are stable and stationary in the given time period. Alternatively, the KPSS test also confirms that the absence of unit root for the corrected series as the null hypothesis for this test cannot be rejected at $95 \%$ confidence level(ranging from 0.12 to 0.45 ).

We conduct Granger causality tests and the results suggest that almost all social media metrics have significant temporal-based causal relationships with the intensity of customer-firm relationship. CommunityA, CommunityQ, No.blogs, Blogfreq, No.miblog and Granger cause the relationship between preliminary customers and the firm ( $\mathrm{p}=0.0014,0.05,0.0001,0.10$ and 0.04 respectively), Searchin. In addition, Communityfreq, No.blogs, No.miblog, Retwitt Granger cause the relationship between stable customers and the firm ( $\mathrm{p}=0.04,0.05,0.0069$ and 0.10 , respectively), No.loyalty. The reverse feedback from metrics of customer-firm relationship to the social media metrics is not significant ( $\mathrm{p}$ value ranging from 0.15 to 0.35). These results confirm the temporal cursal relationship between social media metrics and customer-firm relationship.

\section{Short- and Long-Term Relationship}

We use generalized impulse response function to trace the effect of a unit shock in any one of the variables on the customer-firm relationship metrics. We define the short-term impact as the effect derived from estimates of the VARX model for the first 3 time periods, and the long-term impact 
with 15 time periods. Table 1 presents the results of the short-term and accumulated impact of the metrics of social media on the relationship between preliminary, stable customers and the firm.

Brand Community. Results in Table1 suggest that the firm's efforts in brand communities, CommunityA, has a significant short-term relationship with both preliminary(searchin) and stable $(\Delta$ No.loyalty) customers (1.142,p $<0.05 ; 810.28, \mathrm{p}<0.05$, respectively), and a similar accumulated impact on these two kinds of customer segments(0.699,p $<0.05$; 950.36,p $<0.05)$. This suggests that a change in CommunityA is associated with an increase of the intensity of the customer-firm relationship both in the short and long run. Customer participation in brand communities in terms of asking questions, CommunityQ, positively and significantly influence the connections between the preliminary customers and the firm in both the short term $(1.81, \mathrm{p}<0.05)$ and long term $(1.239, \mathrm{p}<0.05)$. Although Community $Q$ has a positive influence on the stable customer relationship(No.loyalty) both with the short and long term, the impact is not significant(829.86, 1048.88, $\mathrm{p}>0.05)$. As shown in Table 4, customer participation in terms of brand community visit frequency, $\Delta$ Communityfreq, has a positive impact on the preliminary customer relationship(searchin) in the short term $(0.134, \mathrm{p}<0.05)$ and a similar accumulated impact of $0.074(\mathrm{p}<0.05)$, which suggests that a change in customers' brand community visit frequency (Communityfreq) is associated with an increase of the intensity of the preliminary customer relationship both in the short and long term. Although Communityfreq has a positive and significant influence on the stable customer relationship(No.loyalty) with the short term(77.14,p < $0.05)$, the accumulated impact is negative but not significant(-322.3,p $>0.05$ ). These results confirm the relationship between social media metrics in term of brand communities and customer-firm relationship, partially providing evidence for $\mathrm{H} 1$ and $\mathrm{H} 2$.

Web Blog. As shown in Table1, social media metrics in terms of blog posts, No.blogs, has a positive impact on both the preliminary and stable customer relationship, (searchin and $\Delta$ No.loyalty) in the short term (1.241, $\mathrm{p}<0.05 ; 351.41, \mathrm{p}<0.05)$ and a similar accumulated impact of $0.734,25.41$ ( $\mathrm{p}<0.05$ ), which suggests that the firm's efforts in the sites of web blog has positively influenced the connections with both preliminary, stable customers. However, from the results of the GIRFs we can find that the positive effects dissipate gradually, which suggests that social media participation at one period greatly and positively affect the connections between customers and the firm, but will dissipate in the long run. Opposite to the intuitive perception, customer visit frequency in web blogs $(\Delta B \log f r e q)$ does not have a positive influence on the preliminary customer relationship with the short term and a similar accumulated impact $(-0.745,-0.549, \mathrm{p}>0.05)$. The reason is not specific, it maybe relates to the work schedule, for the officers donnot work and interact with customers during the legal holidays, which may cause some skepticism among the preliminary customers. However, it ( $\Delta$ Blogfreq) significantly and positively influence the stable customer relationship with the short term and an accumulated impact of 813.67 and 823.64of daily turnover, respectively $(\mathrm{p}<0.05)$. As such, these results suggest partially empirical evidence for $\mathrm{H} 1$ and $\mathrm{H} 2$, that web blogs in terms of customer participation and active efforts by the firm have a significant positive impact on the customer-firm relationship.

Microblogs. As shown in Table1, social media metrics in terms of microblogs posted by the firm, No.miblog, has a positive impact on both the preliminary and stable customer relationship, (searchin and No.loyalty) in the short term (0.851, p < 0.05; 813.67,p $<0.05$ ) and a similar accumulated impact of 0.627, 820.34(p < 0.05), respectively, which suggests that the firm's active efforts in microblogs posting has positively influenced the connections both with the preliminary and stable customers. However, customer participation in microblogs(retwitt) has a positive influence both on the preliminary and stable customer relationship(searchin, No.loyalty) both with the short and long term, the impact is not significant in the two customer segments relationship with the firm(0.476, 0.209, $\mathrm{p}>0.05 ; 810.28,950.36, \mathrm{p}>0.05)$. As such, these results suggest strong empirical evidence for $\mathrm{H} 1$ and $\mathrm{H} 2$, that social media metrics, web blogs, brand communities and microblogs in particular, in terms of customer participation and social media activity by the firm have a significant positive impact on the customer-firm relationship. 
Table 1 Impulse Responses of customer-firm relationship to Social Media Metrics

\begin{tabular}{|c|c|c|c|c|c|c|}
\hline & \multicolumn{3}{|c|}{ Searchin } & \multicolumn{3}{|c|}{$\Delta$ No.loyalty } \\
\hline & & Wear-inT & $\begin{array}{c}\text { Wear-out } \\
\mathrm{T}\end{array}$ & & Wear-inT & $\begin{array}{c}\text { Wear-out } \\
\mathrm{T}\end{array}$ \\
\hline \multicolumn{7}{|l|}{ Web Blog } \\
\hline \multicolumn{7}{|l|}{$\Delta$ No.blogs } \\
\hline \multirow{2}{*}{$\begin{array}{l}\text { Immediate } \\
\text { Accumulated }\end{array}$} & 1.241 & 2 & 15 & 351.41 & 3 & 14 \\
\hline & 0.734 & & & 25.54 & & \\
\hline \multicolumn{7}{|l|}{$\Delta$ Blogfreq } \\
\hline \multirow{2}{*}{$\begin{array}{c}\text { Immediate } \\
\text { Accumulated }\end{array}$} & -0.745 & 3 & 17 & 119.04 & 2 & 15 \\
\hline & -0.549 & & & -377.25 & & \\
\hline \multicolumn{7}{|l|}{ MicroBlog } \\
\hline \multicolumn{7}{|l|}{$\Delta$ No.miblog } \\
\hline \multirow{2}{*}{$\begin{array}{c}\text { Immediate } \\
\text { Accumulated }\end{array}$} & 0.851 & 2 & 18 & 813.67 & 4 & 15 \\
\hline & 0.627 & & & 820.34 & & \\
\hline \multicolumn{7}{|l|}{ Retwitt } \\
\hline Immediate & 0.476 & 2 & 18 & 1092.34 & 3 & 12 \\
\hline Accumulated & 0.209 & & & 987.4 & & \\
\hline \multicolumn{7}{|l|}{ Community } \\
\hline \multicolumn{7}{|l|}{$\Delta$ CommunityA } \\
\hline \multirow{2}{*}{$\begin{array}{c}\text { Immediate } \\
\text { Accumulated }\end{array}$} & 1.142 & 2 & 17 & 810.28 & 3 & 15 \\
\hline & 0.699 & & & 950.36 & & \\
\hline \multicolumn{7}{|l|}{$\Delta$ Community $Q$} \\
\hline \multirow{2}{*}{$\begin{array}{c}\text { Immediate } \\
\text { Accumulated }\end{array}$} & 1.81 & 2 & 18 & 829.86 & 4 & 13 \\
\hline & 1.239 & & & 1048.88 & & \\
\hline \multicolumn{7}{|l|}{$\Delta$ Communityfreq } \\
\hline Immediate & 0.134 & 2 & 18 & 77.14 & 3 & 15 \\
\hline Accumulated & 0.074 & & & -322.3 & & \\
\hline
\end{tabular}

From the results of the GIRFs, we are able to calculate the elasticity of the connections between preliminary, stable customers with the firm with respect to social media metrics, respectively. Results show that the positive effects on the preliminary customers is stronger than the stable customers, which support empirical evidence for H3.

\section{Relative Importance of Metrics of Social Media}

We use the forecast error variance decomposition of the intensity of customer-firm relationship to assess the relative importance of the various metrics of social media. The decomposition ascertains the extent to which change in various metrics of social media contributes to the deviation of searchin, No.loyalty from baseline expectations. All of the metrics explain nontrivial portions of the variance. The results show CommunityA (27.64\%) to be the most important metric that influences the relationship between preliminary customers and the firm, followed by $\operatorname{No.blogs}(7.4 \%)$ and No.miblog(4.52\%), which suggest that all of the three sources of social media participation greatly influence the customer-firm relationship. Whereas, in terms of the relationship between stable customers and the firm, the results show that CommunityA (3.01\%) to be the most important metric, followed by Communityfreq(1.21\%), which only relates to the metric of brand community. Further, total social media metrics account for a significantly greater proportion of the variance in preliminary customer relationship than stable customer relationship (46.98\% versus $6.19 \%$ ), which strongly support the above hypothesis, H3. 


\section{Discussion}

Our research models the longterm accumulative value of digital user metrics with a time-series technique: the vector autoregressive model with exogenous covariates (VARX).The results indicate that metrics of social media empirically have a impact on the customer-firm relationship, and the wear-in with wear-out effects enable managers to timely terminate ineffective practices and allocate IT budgets to more productive ones across social media. Next, as the results shows, social media investments would pay off the best in terms of establishing and maintaining customer relationships when they actively focus on increasing interaction with customers through brand communities. Further, the impact of social media participation metrics both from the firm and customers' effort on the preliminary customers is stronger than the stable customers, which suggests that different customer segments have different intensions and behave differently in social media metrics hosted by the firm. In this sense, executives should actively interact with those customers who are the new comers or just getting to the brand for a short time periods, while seek new channels beyond efforts on social media metrics to maintain the strong ties.

However, the study suffers from some limitations that can be addressed by future research. First, we are able to provide results from the only IT industry. It would be interesting to study whether the results are generalizable for other companies. Furthermore, in this study, we consider customer behavior in the aggregate perspective. However, it must be interesting to analyze customer behavior in terms of individuals by linking to their demographic and individually specific characteristics.

\section{References}

[1]Parasuraman A, Zeithaml V A, Berry L L. (1985) A conceptual model of service quality and its implications for future research. Journal of marketing. 49(4).

[2]Storbacka K, Strandvik T, Grönroos C. (1994) Managing customer relationships for profit: the dynamics of relationship quality. International journal of service industry management. 5(5): 21-38.

[3]Rishika R, Kumar A, Janakiraman R, Bezawada R (2013) The effect of customers? Social media participation on customer visit frequency and profitability: An empirical investigation. Inform. Systems Res. 24(1):108-127.

[4]Gallaugher J, Ransbotham S (2010) Social media and customer dialog management at starbucks. MIS Quart. Executive 9(4):197-212.

[5]Gupta S, Lehmann DR, Stuart JA (2004) Valuing customers. J. Marketing Res. 41(1):7-18

[6]Swaroop P, Joshi Y V, Rand W M, et al. (2014) Influence in Microblogs: Impact of User Behavior on Diffusion and Engagement. Available at SSRN 2378094.

7]Stieglitz S, Dang-Xuan L. (2013) Emotions and Information Diffusion in Social Media-Sentiment of Microblogs and Sharing Behavior. Journal of Management Information Systems. 29(4): 217-248.

[8]Morgan RM, Hunt SD (1994) The commitment-trust theory of relationship marketing. J. Marketing 58(3):20-38.

[9]Malthouse E C, Haenlein M, Skiera B, et al. Managing Customer Relationships in the Social Media Era: Introducing the Social CRM House[J]. Journal of Interactive Marketing, 2013, 27(4): 270-280.

[10]Kotler P. Reinventing marketing to manage the environmental imperative[J]. Journal of Marketing, 2011, 75(4): 132-135.

[11]Verhoef P C, Reinartz W J, Krafft M. Customer engagement as a new perspective in customer management[J]. Journal of Service Research, 2010, 13(3): 247-252. 